\title{
O Trabalho em um CAPS: um Estudo a Partir da Perspectiva Marxista
}

\author{
Trabajar en un CAPS: un Estudio desde la Perspectiva Marxista
}

\author{
Work in a CAPS: a Study from the Marxist Perspective
}

\section{Maísa Martins Lopes Araújo Brito}

Faculdade Católica Dom Orione (FACDO), Araguaína - TO/Brasil

ORCID: 0000-0002-0954-4624

E-mail: maisamlab@gmail.com

\author{
Samuel de Menezes Pereira \\ Faculdade Católica Dom Orione (FACDO), Araguaína - TO/Brasil \\ ORCID: 0000-0003-0188-7283 \\ E-mail: samuel.mnz12@gmail.com
}

Gilson Gomes Coelho

Faculdade Católica Dom Orione (FACDO), Araguaína - TO/Brasil ORCID: 0000-0002-0110-4456

E-mail: gilsonpsico@gmail.com

\begin{abstract}
Resumo
Este artigo trata de um relato de experiência sobre um Estágio Básico Supervisionado em Psicologia Organizacional realizado em um CAPS (Centro de Atenção Psicossocial) do Tocantins. O objetivo do trabalho foi compartilhar o levantamento de demandas organizacionais e possíveis soluções para as mesmas observadas no decorrer da experiência. Foram verificados, através de observações orientadas no decorrer de um semestre e revisão de literatura, comportamentos contraproducentes e destoantes do que preconizam as políticas públicas de saúde mental. Com base em um referencial teórico marxista, foi possível perceber que esses comportamentos podem ser produtos de processos históricos e sociais específicos que balizam o fazer profissional na sociedade capitalista, tendo a alienação do trabalho e a perda de sentido da atividade como produto. Assim, um foco de trabalho possível a curto prazo seria a reapropriação das teorias e referenciais que alicerçam a dinâmica de funcionamento da organização. A experiência permitiu conhecer as contradições presentes na prática profissional e pensar novas formas de superá-las.
\end{abstract}

Palavras-chaves: Estágio; Psicologia organizacional; Marxismo.

\section{Resumen}

Este artículo es un informe de experiencia sobre una pasantía básica supervisada en psicología organizacional realizada en un CAPS (Centro de atención psicosocial) de Tocantins. El objetivo del trabajo fue compartir la encuesta de demandas organizacionales y las posibles soluciones a las mismas observadas durante la experiencia. A través de observaciones orientadas durante un semestre y revisión de la literatura, se verificaron comportamientos contraproducentes que eran contrarios a las políticas públicas. Basado en un marco teórico marxista, fue posible darse cuenta de que estos comportamientos pueden ser el producto de procesos históricos y sociales específicos que guían la actuación profesional en la sociedad capitalista, con la alienación del trabajo y la pérdida de significado de la actividad como producto. Por lo tanto, un posible foco de trabajo a corto plazo sería la reapropiación de las teorías y referencias que subyacen a la dinámica del funcionamiento de la organización. La experiencia nos ha permitido conocer las contradicciones presentes en la práctica profesional y pensar en nuevas formas de superarlas.

Palabras clave: Pasantía; Psicología organizacional; Marxismo.

\footnotetext{
Abstract

This article is an experience report about a Supervised Basic Internship in Organizational Psychology held at a Tocantins Psychosocial Care Center. The objective of the work was to share the survey of organizational demands and possible solutions to them observed during the experience. Through oriented observations during a semester and literature review, counterproductive behaviors that were contrary to public policies were verified. Based on a Marxist theoretical framework, it
} 
was possible to realize that these behaviors can be the product of specific historical and social processes that guide professional doing in capitalist society, with the alienation of work and the loss of meaning of activity as a product. Thus, a possible focus of work in the short term would be the reappropriation of theories and references that underlie the dynamics of the organization's functioning. Experience has allowed us to know the contradictions present in professional practice and to think of new ways to overcome them.

Keywords: Internship; Organizational Psychology; Marxism.

\section{Contextualização}

$\mathrm{O}$ artigo que se segue nasce a partir da prática e revisão teórica do Estágio Básico Supervisionado em Psicologia Organizacional em um Centro de Atenção Psicossocial no norte do Tocantins. A escolha do local foi feita a partir de inquietações acerca do funcionamento e devida aplicação das políticas públicas de saúde mental no estado. O estágio teve como objetivo o levantamento de demandas organizacionais a partir da observação do cotidiano do trabalho em um Centro de Atenção Psicossocial, com enfoque na atuação dos profissionais de psicologia, analisando se as práticas eram condizentes com o que preconizam os referenciais teóricos.

A partir disso, tem por finalidade compartilhar as revisões teóricas feitas no decorrer da observação, as problemáticas levantadas e possíveis saídas para as mesmas. Se divide em uma pequena explicação da metodologia utilizada, seguida por uma explanação teórica dos materiais utilizados para fundamentar o olhar dos estudantes, subdividida em 1) relação psicologia-trabalho; 2) os modelos de produção capitalista e a produção do sofrimento psíquico; 3) a psicologia nas organizações e 4) o psicólogo no Centro de Atenção Psicossocial; por último, são apresentados os dados observados e é feita uma pequena discussão sobre eles.

\section{Metodologia}

Dentro da disciplina de Estágio Básico Supervisionado com ênfase em Psicologia Organizacional, foram oferecidas possibilidades de campo diversas. Partindo de uma identificação com Centro de Atenção Psicossocial e respectiva vontade de conhecer a realidade e atuação do profissional de psicologia no mesmo, o objeto de estudo foi delineado. A partir disso, os estagiários buscaram aproximação com o coordenador do órgão, explicando como se daria o processo, firmando um convênio através da assinatura de um Contrato de Estágio e um Termo de Compromisso pelos estagiários.

Tendo que cumprir uma carga horária de $70 \mathrm{~h}$ obrigatórias, sendo $30 \mathrm{~h}$ práticas, $30 \mathrm{~h}$ de supervisão e $10 \mathrm{~h}$ de escrita, as visitas de observação ao CAPS foram divididas em 10 semanas, com uma ida com duração de três horas em cada uma delas. Analisando o cronograma disponibilizado, foi dada preferência para os dias e horários em que aconteceriam oficinas dos psicólogos, totalizando seis dias no período matutino e quatro no vespertino. Contudo, antes de partir para a parte prática, as orientações se voltaram para leitura dos referenciais teóricos de psicologia organizacional e marxistas explorados no decorrer deste relato, corroborando com Cruz Neto (2002), que aponta a necessidade de uma base teórica para olhar os dados da realidade dentro de um quadro de referências.

Foi, dessa forma, escolhida a metodologia qualitativa do tipo descritiva, objetivando a descrição das características do fenômeno, além de traçar possíveis relações entre variáveis observadas com o referencial teórico (Gil, 2008). Entendendo que, enquanto acadêmicos, os estagiários precisam observar detalhadamente a realidade, antes de praticá-la, se estabeleceu um trabalho de campo, utilizando a técnica da observação participante, onde se realizou o contato direto do pesquisador com o fenômeno a ser observado para obter informações sobre a realidade dos 
próprios atores sociais em seu contexto (Cruz Neto, 2002).

Para o registro do observado, utilizaram-se relatórios semanais e individuais que foram lidos, corrigidos e debatidos com o orientador nos encontros também semanais. Essa parte foi de fundamental importância, pois eram compartilhadas as impressões, angústias e demandas observadas que, confrontadas com a teoria e avaliação do professor, se tornaram mais nítidas. Por fim, a perspectiva marxista, que acompanhou o processo de estágio do começo ao fim, foi escolhida porque Marx se mantém atual, na medida em que consegue, através do que escreveu há tanto tempo, estimular novas ideias. Sua análise fornece elementos que, se atualizados e aplicados nos dias de hoje, ajudam a explicar o momento presente, dando caminhos para transformá-lo (Musto, 2016). A análise marxista, segundo Guzzo (2016), revela a ideologia que impregna a vida cotidiana com sofrimento, exploração e violência, sendo então necessário para guiar o olhar de quem se pretende a perceber o mundo de uma forma crítica e emancipadora.

\section{A relação psicologia-trabalho}

A relação psicologia-trabalho possui uma multiplicidade de expressões que a nomeiam: psicologia do trabalho, psicologia organizacional, psicologia aplicada ao trabalho, sinalizando assim a variedade teórica e prática no qual é permeada (Leão, 2012). A partir disso, Zanelli, Borges-Andrade e Bastos (2004) a definem como campo de compreensão e intervenção sobre o trabalho nas organizações para analisar a interação das dimensões pessoais, grupais e organizacionais, podendo assim construir estratégias para promoção, preservação e estabelecimento do bem-estar.

A trajetória histórica e conceitual da categoria trabalho não é linear, mas dependente de seus contornos geográficos, econômicos e políticos, tendo como características principais a multi e interdisciplinaridade, a inexistência de coesão conceitual e prática e a simultaneidade de diversas matrizes epistemológicas onde, embora o objeto de estudo comum sejam os fenômenos relativos aos processos organizacionais e do trabalho, essas correntes orientam como abordá-lo (Leão, 2012).

Segundo o autor citado anteriormente, a psicologia organizacional pode ser entendida como um campo de compreensão e intervenção das várias dimensões que formam as pessoas, os grupos e as organizações, tendo como finalidade construir estratégias e procedimentos que promovam, preservem e reestabeleçam o bem-estar. Trabalhando as relações de poder, de gênero, os impactos psicossociais do desemprego, saúde, alienação, interação social, problematizando os modelos formalizados de produção, entre outros. Visando compreender e intervir no fenômeno do mundo do trabalho, partindo de referências críticas e não positivistas, implicando na transformação da sociedade e na emancipação humana.

Tendo em vista o grande escopo teórico que envolve o trabalho, foi destacado a concepção marxista para estruturar todo este texto, devido ao seu método materialista histórico de análise da sociedade, abarcando assim as contradições da mesma. Karl Marx, ao pensar a filosofia como uma forma de não apenas explicar, mas transformar a realidade (Marx, 1845/1998), elege o trabalho como categoria central de sua teoria.

Pressupomos o trabalho numa forma em que ele diz respeito unicamente ao homem. Uma aranha executa operações semelhantes às do tecelão, $\mathrm{e}$ uma abelha envergonha muitos arquitetos com estrutura de sua colmeia. Porém, o que desde o início distingue o pior arquiteto da melhor abelha é o fato de que o primeiro tem a colmeia em sua mente antes de construí-la com a cera. No final do processo de trabalho, chega-se a um resultado que já estava presente na representação do trabalhador no início do processo, portanto, um resultado que já existia idealmente. (Marx, 1867/2013, pp. 255-256). 
Para ele, o mesmo é a expressão máxima de criação e realização da vida humana. O que os homens produzem é o que eles são, pois ao mesmo tempo que transformam a natureza, transformam a si mesmos. O trabalho é exclusivamente humano, pois primeiro se realiza na imaginação, é planejado. Deste modo, se lhe é privado o projeto e a visão antecipada do produto, o trabalho é desumano (Albornoz, 2008).

O trabalho enquanto criador de valorde-uso é indispensável à existência do homem, sendo uma necessidade natural (Marx, 1867/2013) mas as transformações na sociedade urbano-industrial causaram mudanças na base técnica subjetiva do processo de trabalho para uma base objetiva, racionalizando o controle do trabalho pela mecanização e informatização, buscando aumentar a produtividade. Assim, há a ruptura da relação homem e natureza, passando estes a ser apenas recursos instrumentais do processo (Franco, 2011).

A partir disso, a valorização do mundo das coisas aumenta na mesma proporção que a desvalorização do mundo dos homens, transformando o trabalho em produtor de si mesmo e do homem como mercadorias (Marx, 1867/2013). Consequentemente, a atividade perde sua função primeira, se configurando como alienadora:

Em primeiro lugar, o trabalho é exterior ao trabalhador, quer dizer, não pertence à sua natureza; portanto ele não se afirm a no trabalho, mas nega se a si mesmo, não se sente bem, mas infeliz, não desenvolve livremente suas energias físicas e mentais, mas esgota-se fisicamente e arruína o espírito. Por conseguinte, o trabalhador só se sente em si fora do trabalho, enquanto no trabalho se sente fora de si. Assim, o seu trabalho não é voluntário, mas imposto, é trabalho forçado. Não constitui a satisf ação de uma necessidade, mas apenas um meio de satisfazer outras necessidades. $\mathrm{O}$ seu caráter ressalta claramente do fato de se fugir do trabalho como da peste [...] Se o produto do trabalho não pertence ao trabalhador, se a ele se contrapõe como um poder estranho, isso só é possível porque o produto do trabalho pertence a outro homem distinto do trabalhador. (Marx, 1844/1993, pp. 157-172).

Partindo desse conceito de alienação, se é possível compreender os processos de adoecimento causados no e pelo trabalho. A visão marxista, dessa forma, não é apenas o meio de acesso as demandas da classe trabalhadora para entender as organizações, mas também de base sólida para colocar em prática a emancipação humana um novo horizonte de autenticidade e de produção teórica (Cunha, \& Ferraz, 2015).

\section{Os modelos de produção capitalista e a produção de sofrimento psíquico}

O percurso histórico do Trabalho nas ciências sociais surge a partir de Revolução Industrial (século XVIII), onde, juntamente com os processos de industrialização e urbanização, emergem problemas sociais de degradação das condições de vida e trabalho. A Psicologia nesse contexto surge para facilitar a administração de pessoas, resolver problemas individuais e coletivos ligados à indústria, dando início à chamada Psicologia Industrial, que contribuiu para a noção de trabalho de cunho econômico difundida pelo capitalismo (Leão, 2012).

Saindo da Psicologia Industrial, influenciada por conceitos da sociologia, antropologia e pelo desenvolvimento da psicologia social, a categoria organização entra como elemento central para o campo das relações psicologia-trabalho, onde os problemas tradicionais como recrutamento, seleção e condições de trabalho passam a ser tratados como relacionados entre si e ligados ao sistema social, ao mesmo tempo que considera a organização como um sistema complexos, formada por uma nova série de problemas não mais individuais (Schein, 1969). 
Em solo Europeu, segundo Leão (2012), surge uma contribuição crítica à relação psicologia-trabalho em análises que vinculam o tema ao marxismo, problematizando as formas de produção da subjetividade e seus novos objetos frente ao contexto político social da década de 1960, convocando os trabalhadores como agentes da ação e dando centralidade a sua subjetividade.

No Brasil, influenciados pela psicologia social sociológica e a abordagem sóciohistórica, surgem estudos dos mais variados fenômenos do trabalho, problematizando a mesma como reprodutora das relações de poder de forma elitista e individualizante, apontando para o trabalho como elemento fundamental para compreender os processos psicossociais, assumindo o compromisso na transformação social e emancipação do ser humano (Veronese, 2003). Nesse sentido, entendendo que, como dito acima, o ser humano se constitui como ser social a partir de seu trabalho, se torna necessário se apropriar dos principais aspectos históricos dos modelos de produção capitalistas para assim assimilar suas consequências psicológicas.

Após introduzir o dia de trabalho de oito horas e cinco dólares como recompensa para os trabalhadores em 1914, Ford inicia o que para ele era mais que um modelo de produção, mas também um modelo de sociedade. $\mathrm{O}$ fordismo reconhecia que a produção em massa significava consumo em massa, uma nova política de controle, estética e psicologia do trabalho. Introduzindo, a partir daí, sua linha de montagem móvel: a esteira, controlando o tempo do trabalho e o fragmentando, se aprofunda a partir daí a divisão do trabalho e a falta de responsabilidade do trabalhador pelo produto final, sendo considerado assim um custo móvel, facilmente substituídos (Harvey, 1993).

Na mesma época, é publicado em 1911, o livro Os Princípios da Administração Científica de Taylor, onde descreve o modelo de produção taylorista, que busca aumentar a produtividade a partir da decomposição dos processos de trabalho e organização de tarefas fragmentadas em tempos e movimentos rigorosos, o que já havia sendo implementado nas fábricas por Ford. Entendendo que ambos os modelos vigentes têm consequências na vida dos trabalhadores e que se complementam como prática e teoria, Marochi (2002) evita distinção entre os mesmos para falar de seus aspectos psicológicos.

Para ser posto em prática, esse modo operatório cientificamente estabelecido por Taylor exigia algumas condições, entre elas a repressão da chamada vadiagem (queda de produção) no trabalho e a dominação do modo de fazer desses trabalhadores, implantando assim modos de trabalhos mais rápidos $\mathrm{e}$ eficientes para todos os trabalhadores, sem distinção de idade, altura e sexo. Assim, ele desapropria os trabalhadores de seu saber no trabalho, da originalidade da invenção e da liberdade do processo produtivo como um todo (Dejours, 1987). Já isolado devido à divisão do trabalho, o trabalhador é privado de exercer as capacidades que o tornam humano.

Partindo da necessidade de produzir veículos competitivos, mas em um volume reduzido, nasce do outro lado do globo o toyotismo. Esse sistema se caracterizava, entre outras coisas, pela execução de diversas atividades pelo mesmo funcionário, causando sentimentos de responsabilidade e comprometimento, além de um constante aperfeiçoamento no trabalho e a valorização da experiência (Womack, Jones, \& Roos, 1992).

Relacionando com os outros modelos supracitados, a equipe se sobressai ao indivíduo no toyotismo, ocasionando uma maior participação do trabalhador no processo produtivo. Além disso, aqui há a possibilidade de um trabalhador assumir a liderança em determinadas questões, perceber e analisar os problemas relativos ao trabalho, melhorar habilidades de comunicação e administração de conflitos, entre outros (Tractenberg, 1999). Esse modelo, porém, exige uma posição contraditória do trabalhador que assume cargos de gerência, como ser competitivo e cooperativo, individualista e que saiba 
trabalhar em equipe gerando uma instabilidade emocional.

É possível observar que, conforme o período histórico, a localização geográfica e demais determinantes culturais e sociais em que se estabelece, o trabalho e as relações decorrentes dele se organizam de uma forma específica podendo, com isso, gerar consequências nas esferas individuais e grupais do ser humano.

\section{A Psicologia nas organizações}

A Organização, partindo de Robbins, Judge e Sobral (2010), é uma unidade social constituída de uma ou mais pessoas, onde, coordenadas conscientemente, visam atingir objetivos próprios. As organizações são grupos coletivos guiados para alcançarem objetivos específicos, existindo uma ação coordenada dos indivíduos do grupo envolvido, essas ações demandam critérios específicos para selecionar as atividades que devem ser desenvolvidas:

[...] as organizações são o modo como as pessoas e os grupos se estruturam para atender às suas próprias necessidades. Seu funcionamento depende do trabalho humano, que, por sua vez, tem sido também mais dependente das organizações, à medida que crescem a complexidade das tarefas e a necessidade de recursos, que só encontramos em nível organizacional. (Zanelli et al., 2004, p. $550)$.

Petit e Dubois (1998) definem como principais dimensões da organização: sistema/relação entre a organização e a vida institucional, o funcionamento dos grupos na organização e as relações complexas entre o indivíduo e a organização. Esta é um sistema social formado por várias esferas, sendo elas física, econômica, política e cultural, não se resumindo apenas a uma soma de indivíduos, oficinas ou serviços, mas à coexistência dessas partes necessariamente interligadas, existindo uma relação de interdependência para a realização de um objetivo em comum. Essa relação forma a unidade da organização, dessa forma, a mudança de um acarreta a mudança de todos, assim mudando todo o ambiente.

A Psicologia Organizacional, entendida como o estudo científico do comportamento humano nas organizações de trabalho, se insere como uma área de aplicação dos princípios e metodologias propriamente psicológicos neste contexto:

[...] emerge das interações entre comportamento no trabalho e a organização. Seu interesse central é entender e lidar com os processos psicossociais que caracterizam as organizações de trabalho como conjuntos de pessoas cujas ações precisam ser coordenadas a fim de atingir metas e objetivos que definem a missão de uma organização. (Zanelli et al., 2004, pp. 562-563).

O papel do profissional da psicologia está sempre em discussão e estudos pelos próprios atuantes da área e, como citam Bastos e Martins-Galvão (1900), esses estudos buscam não só perceber os princípios histórico-sociais que moldam o perfil de atuação do psicólogo brasileiro, mas também questionam os aspectos práticos, como meio de construir um novo modelo de atuação mais coerente com a realidade sócio-política na qual o profissional está incluído.

Os autores supracitados também assinalam que o fazer do profissional dentro de uma organização está ligado em questões voltadas ao desempenho de pesquisas com equipe multiprofissional, visando um campo maior de conhecimento e atualização de técnicas para a Psicologia Organizacional, preparação do ambiente, organização das políticas dos Recursos Humanos (RH), realização de práticas de aperfeiçoamento (atualização da sua profissão) e reciclagem profissional (aquisição dos conhecimentos, capacidades e atitudes, dentro da mesma profissão) e desenvolvimento de programas para que promovam uma adequada alocação (reorganizar ou distribuir os funcionários que já 
estão na organização em novas tarefas) e um controle sobre a vida funcional do trabalhador (padronização da execução de tarefas, possibilita aos servidores atendimento cada vez mais humanizado, fluxo de informações, ciência dos direitos e conhecimento deles).

No campo das organizações o psicólogo tem a possibilidade de atuar trabalhando no clima organizacional, mediando conflitos e gerando estratégias para melhorar as habilidades e potencializando a dinâmica do grupo (Lemos, Neto, Barbora, Pereira, Ferreira, \& Valerio, 2007). O Conselho Federal de Psicologia (CFP, 2013) afirma que é a $2^{\circ}$ área de maior atuação e reforça a ideia de que o psicólogo deve atuar nesses espaços, pois, a mesma pode ajudar a sociedade a enfrentar questões contemporâneas, visto que o trabalho passou a ser uma das principais fontes de formação de vínculos.

Entendendo que, dentro dos princípios do sistema capitalista, se destacam a produtividade, eficiência e competitividade e a psicologia, inserida no cenário das organizações, não está isenta de reproduzi-los, mesmo com todos os avanços nos contextos econômico, social, cultural e tecnológico. Pois, conceitualmente, está ligada diretamente à métodos tradicionais como recrutamento, seleção e treinamento (Pereira, 2009).

Esses métodos estão intrinsecamente ligados ao meio de produção capitalista, pois o trabalho consiste na valorização do capital com o objetivo na produção da mais-valia ${ }^{1}$. Prolongando a jornada de trabalho, aumentando sua força produtiva, alterando o meio de trabalho ou seus métodos e por meio da inovação das tecnologias, reduzindo assim o valor da mercadoria e da força de trabalho (Marx, 1859/2008).

\footnotetext{
${ }^{1}$ A pedra angular da teoria econômica de Marx. Segundo ela, o operário, ao vender sua força de trabalho ao patrão, emprega uma parte do dia para cobrir o custo de seu salário; durante do resto do dia, trabalha gratuitamente, criando a mais-valia, fonte dos lucros e riquezas da classe capitalista (Lénine, 1913).
}

Segundo Braverman (1981) o meio de impedir o controle do processo de trabalho pelos trabalhadores é a falta da relação entre o trabalho intelectual e o trabalho manual, desqualificando o trabalhador pela nova natureza de trabalho apresentada, reduzindo as tarefas rotineiras e simples por tarefas cada vez mais específicas e sem conteúdo. Assim como na esteira rolante do fordismo, que reorganizou o local de trabalho colocando em um ponto fixo e realizando os mesmos movimentos.

Azevedo e Cruz (2006) assinalam que a imagem do psicólogo brasileiro está ligada ao modelo curativista, procurado apenas quando aparecem sintomas, que desembocam na busca de soluções rápidas (fazendo com que o trabalhador volte a produzir mais em um curto espaço de tempo) e analisando uma única parte sem observar o todo. Todavia, o psicólogo deve atuar investigando o todo, levantando hipóteses das situações do ambiente organizacional, sem interpretações reducionistas ou sem eficácia.

A atuação pode ser dividida em três níveis, sendo eles: técnico, geralmente mais superficial, em que o psicólogo intervém através de instrumentos ou procedimentos conhecidos; estratégico, que faz com que o profissional faça da formulação de estratégias que integre aquela atividade específica; político, que dá a possibilidade de intervenção nas políticas globais da organização. Surge assim um movimento de inovações na psicologia organizacional, desde os seus procedimentos aos modos de atuar, tornando o papel do psicólogo mais abrangente, tentando entender os comportamentos das pessoas que trabalham, uma possível construção produtiva das ações do trabalho, a preservação máxima da natureza, na qualidade e o bem-estar da vida e social (Zanelli et al., 2004). 


\section{O psicólogo no Centro de Atenção Psicossocial}

Para entender e analisar a dinâmica organizacional do CAPS, é necessário entender um pouco das leis que o fundamentam. Como resultado da luta antimanicomial e buscando um cuidado para além do hospital, normatização do CAPS tem como princípio fundante a Lei $\mathrm{n}^{\circ} 10.216$, de 6 de abril de 2001, que é um marco para a garantia de direitos e a proteção das pessoas acometidas por transtorno mental. Nesta lei, as pessoas são asseguradas sem qualquer tipo de discriminação quanto à cor, raça, sexo, orientação sexual, religião, nacionalidade, opção política, idade, família, recursos econômicos, e ao grau de gravidade ou tempo de evolução de seu transtorno. Disponibiliza o acesso ao melhor tratamento do sistema de saúde de acordo com suas necessidades, objetivando um tratamento com humanidade e respeito para alcançar a recuperação inserido no contexto familiar, no trabalho e socialmente, protegido contra qualquer forma de abuso ou exploração.

Considerando a lei supracitada, em 19 de fevereiro de 2002 é estabelecida a portaria $n^{\circ}$ 336, que designa que os Centros de Atenção Psicossocial [CAPS] poderão constituir-se nas seguintes modalidades de serviço: CAPS I, CAPS II e CAPS III. Definidos em ordem de complexidade e abrangência populacional, cumprindo as mesmas funções no atendimento ao público de saúde mental no seu território, com regime intensivo, semi-intensivo e não intensivo. A responsabilidade da organização da demanda e da rede de cuidado em saúde mental no âmbito do território fica sob coordenação local, havendo quadro de profissionais capacitados e de nível superior, tais como: psicólogo, assistente social, enfermeiro, terapeuta ocupacional, pedagogo.

A entrada dos psicólogos, centro da observação neste trabalho, nos serviços de saúde pública envolveu, segundo Lima (2005), alguns fatores: o contexto das políticas públicas no final dos anos 70 e início dos anos 80, a diminuição da busca por consultórios devido ao empobrecimento, na mesma época, o movimento crescente na categoria para redefinir a função social da profissão e a difusão da psicologização da sociedade. Dentro da saúde pública, em especial nos CAPS, o psicólogo assume atribuições como a preparação do doente mental para a reinserção social, sua manutenção na comunidade, a orientação da família, a participação na formação dos demais trabalhadores, além de criar medidas que interviram na vida dos pacientes, permitindo com que criem vínculos com a comunidade (Kubo, \& Batomé, 2001).

Entretanto, apesar das décadas transcorridas desde essa entrada inicial, até hoje esse trabalho é perpassado por dificuldades decorrentes de uma formação ainda focada na clínica, um instrumental teórico-prático insuficiente para a nova realidade, dificuldade de compor equipes multiprofissionais e as próprias adversidades existentes no órgão. É necessário um constante questionamento do tradicional frente ao novo para que esses impasses e desafios sejam superados (Cantele, Arpini, \& Roso, 2012).

\section{Resultados e discussão}

Após o encerramento das observações em campo e a análise do material escrito nos relatórios, o referencial teórico e as orientações, se destacaram alguns pontos considerados importantes por nós para pensar as demandas organizacionais do CAPS. Essas, foram divididas em pequenos blocos, para facilitar a compreensão e análise: 1) oficinas terapêuticas; 2) discursos religiosos; 3) dinâmica de funcionamento.

As oficinas terapêuticas são dadas pelos psicólogos, em seus respectivos turnos. A do período matutino que tem como foco a escrita de poesias, só aconteceu em quatro dias dos seis que reservamos para participação, sem nenhuma explicação do psicólogo - que estava no CAPS - sobre os motivos para a nãorealização para os estagiários e usuários. Nos quatro dias escolhidos para participar das oficinas no período vespertino, apenas em um ela ocorreu, durando menos da metade do tempo estipulado no cronograma. 
Nos dias em que foi possível fazer a observação, alguns pontos foram elencados como problemáticos: alguns usuários eram impedidos de ler suas poesias em voz alta por serem "pesadas demais"; os usuários não receberam explicações sobre a finalidade do que estavam fazendo nem puderam escolher os temas para as poesias, sendo um previamente escolhido pelo psicólogo, muitos se aborreciam de estar sendo obrigados a ficarem naquele espaço. Para Grigolo, Peres, Garcia Junior e Rodrigues (2015), isso mostra que o terapêutico se perdeu, pois a repetição de uma atividade sem sentido para o usuário faz a ação se perder em si mesma.

Os discursos religiosos foram observados em todos os dias de ida a campo. De manhã, antes do café da manhã, é feito o devocional (momento de oração) por algum dos funcionários, onde os usuários e eles se juntam para fazer uma oração, todas as vezes observadas de cunho cristão-evangélico. Além de músicas e comentários religiosos feitos pelos funcionários no local de trabalho.

A dinâmica de funcionamento foi, talvez, o principal ponto de observação. Por três vezes, com usuários diferentes, eram marcadas consultas - psicológicas e médicas - e o profissional não aparecia nem explicava a ausência para o usuário, tendo que ser remarcadas. Em um dos casos, dois indígenas vieram do Centro de Apoio à Saúde do Índio [CASAI], passaram a manhã inteira no órgão e ninguém perguntou para eles o que estavam esperando. Ao serem questionados sobre isso, os funcionários apontaram para uma má organização e comunicação de quem marca as consultas e quem as executa.

Com base nas observações feitas, foram identificados comportamentos denominados por Spector (2012) como comportamentos produtivos e comportamentos contraproducentes. Os comportamentos produtivos, segundo o autor supracitado, estão ligados ao papel individual de cada funcionário para que a organização realize seus objetivos de forma razoável. No setor das políticas públicas, implica dizer que, se esses comportamentos não forem alcançados, o serviço público terá um mal desempenho, deixando de prestar os serviços essenciais. Para que esse trabalho seja exercido de forma razoável, o funcionário deve apresentar aptidões, habilidades e motivação para realizar seu papel de forma coerente com as demandas exigidas pela organização e demonstrar um comportamento de cidadania organizacional, indo além das suas atividades dentro da organização, como, ajudar os supervisores, fazer sugestões inovadoras e ser pontual.

Quando estes comportamentos não são alcançados, percebe-se outros tipos, os contraproducentes, sendo relacionados entre outras coisas, ao abandono de função, realização incorreta ou não realização do que é proposto. Foi possível verificar ao longo da presença em campo, como exemplo destes, funcionários fazendo uso excessivo do celular, conversando sobre suas vidas pessoais na sala da administração enquanto usuários esperavam do lado de fora, jogando tênis de mesa e realizando outras atividades que não estavam ligadas ao trabalho, além do frequente descumprimento das atividades contidas no cronograma. Essas ações acabaram prejudicando a organização e a outras pessoas, como colegas e usuários.

Segundo o referencial teórico que baseia este relatório, esses comportamentos não aparecem por acaso ou são unicamente de responsabilidade individual dos trabalhadores, mas surgem a partir de processos históricos e sociais que balizam o fazer profissional na sociedade capitalista, que tem a alienação do trabalho como produto. Este trabalho alienado é dividido por Franco (2011) em quatro aspectos: 1) o trabalho sem arte; 2) o trabalho dominado; 3) a perda da razão social do trabalho e 4) o ser humano desenraizado. Destas, as duas últimas podem ser visualizadas na problemática apresentada: ao perder o produto final de seu trabalho, sem ter a plena consciência de qual é a sua função, o trabalho deixa de fazer sentido para o homem, alienando também a si mesmo, não se sentindo parte daquilo que realiza. 
Além do funcionamento do órgão como um todo, a observação foi mais especificamente direcionada ao fazer profissional dos psicólogos. Com o olhar fundamentado pelas Referências Técnicas do CREPOP, foi possível perceber algumas práticas não condizentes com o que preconiza o Conselho Federal de Psicologia, como discursos patologizantes, oficinas sem embasamento teórico e metodológico, frases motivacionais que desprezam o histórico e as condições materiais de existência em que o sujeito se encontra, discursos religiosos e a redução do indivíduo ao seu vício.

A prática do estágio foi importante para entender as contradições pertencentes à prática profissional, onde as condições materiais dificultam o cumprimento e efetivação do que versa a teoria ou, dependendo da realidade, a formação precarizada não leva em consideração que esses futuros profissionais atuarão nas políticas públicas. Dessa forma, foi importante para relembrar a importância de uma formação crítica, da articulação entre teoria e prática e a necessidade de uma análise da realidade a partir do materialismo-histórico, para compreendê-la em seu movimento e poder transformá-la.

\section{Considerações finais}

A partir do prisma materialista histórico-dialético, a realidade é formada por contradições e um olhar marxista, dessa forma, deve estar atento para não só encontrá-las, mas entender a conjuntura sócio-histórica que as estabelece e, por fim, transformá-las. Nesse sentido, não basta apontar a distância entre as práticas realizadas no CAPS e o que é preconizado pelas políticas públicas de saúde mental, é preciso sinalizar saídas concretas e possíveis.

No que tange ao cenário atual, há um corrente retrocesso nas conquistas da luta antimanicomial e da saúde pública como um todo desde as últimas eleições, cujo resultado favoreceu um projeto de privatização do Estado, congelamento de investimentos de políticas sociais, retirada de direitos trabalhistas e demais mudanças que afetam diretamente a classe trabalhadora, em especial os servidores públicos.

Entendendo que o trabalho alienado foi o eixo principal das demandas elencadas, bem como a ausência de sentido na atividade, um foco de trabalho possível a curto prazo dentro dessa conjuntura obscura seria a reapropriação das políticas públicas de saúde mental, redução de danos, direitos humanos e outras que deveriam alicerçar a dinâmica de funcionamento da organização. Como exemplo disso, podem ser inseridos periodicamente no cronograma de atividades grupos de estudos e discussões de caso entre os funcionários, rodas de conversas com os usuários para uma devolutiva do que está sendo feito e o que pode melhorar e criação de espaços que fomentem a criação e fortalecimento de vínculos.

\section{Referências}

Albornoz, S. (2008). O que é trabalho (9a. ed.) São Paulo, Brasil: Brasiliense.

Azevedo, B. M., \& Cruz, R. M. (2006). O

processo de diagnóstico e de intervenção do psicólogo do trabalho. Cadernos de

Psicologia Social do Trabalho. 9(2), 89-98.

Recuperado de

http://pepsic.bvsalud.org/scielo.php?script= sci_arttext\&pid=S151637172006000200007
Bastos, A. V. B., Martins-Galvão, A. H. C. G. (1990). O que pode fazer o psicólogo organizacional. Psicologia: Ciência e Profissão, 10(1), 10-18. doi: 10.1590/S1414-98931990000100005

Braverman, H. (1981). Trabalho e o capital monopolista (N. C. Cadeixo, Trad.) (3a. ed.). Rio de Janeiro, RJ: Editora Guanabara.

Cantele, J., Arpini, D. M., \& Roso, A. (2012). A psicologia no modelo atual de atenção 
em saúde mental. Psicologia: Ciência e

Profissão, 32(4), 910-925. doi:

10.1590/S1414-98932012000400011

Conselho Federal de Psicologia [CFP]. (2013).

Cartilha Avaliação Psicológica (vol.1).

Brasília, DF: CFP.

Cruz Neto, O. O trabalho de campo como descoberta e criação. In M. C. S. Minayo (Org.), S. F. Deslandes, O. Cruz Neto, \& R. Gomes. (2002), Pesquisa social: teoria, método e criatividade (pp. 51-66, 21a. ed.). Petrópolis, RJ: Editora Vozes.

Cunha, E., \& Ferraz, D. L. S. (2015). Marxismo, Estudos Organizacionais e a luta contra o irracionalismo. Revista $O \& S$, 22(73), 193-196. doi: 10.1590/19849230730

Dejours, C. (1987). A loucura do trabalho (A. I. Paraguay e L. L Ferreira, Trad., 2a. ed.). São Paulo, SP: Cortez-Oboré.

Franco, T. (2011). Alienação do trabalho: despertencimento social e desrealizamento em relação à natureza. Caderno $C R H$, 24(01), 171-191. doi: 10.1590/S010349792011000400012

Gil, A. C. (2008). Métodos e técnicas de pesquisa social (6a. ed.). São Paulo, SP: Editora Atlas S.A. (Original publicado em 1987).

Grigolo, T., Peres, G. M., Garcia Junior, C. A., \& Rodrigues, J. (2015). O projeto terapêutico singular na clínica da atenção psicossocial. Cadernos Brasileiros de Saúde Mental, 7(1), 53-73. Recuperado de https://periodicos.ufsc.br/index.php/cbsm/ar ticle/view/68912

Guzzo, R. S. L. (2016). Marxismo e pesquisa: apontamentos sobre a experiência de um Grupo de Pesquisa em Psicologia. In I. F. Oliveira, I. L. Paiva, A. L. F. Costa, K. Amorim, \& F. Coelho-Lima (Orgs.), Marx hoje: pesquisa e transformação social (pp. 245-254). São Paulo, SP: Outras Expressões.

Harvey, D. (1993). Condição pós-moderna (2a. ed.) São Paulo, SP: Loyola.

Kubo, O. M., \& Batomé, S. P. (2001). Formação e atuação do psicólogo para o tratamento em saúde e em organizações de atendimento à saúde. Interação em
Psicologia, 5, 93-122. doi:

10.5380/psi.v5i1.3319

Leão, L. H. (2012). Psicologia do Trabalho: aspectos históricos, abordagens e desafios atuais. ECOS,2(2), 292-305. Recuperado de http://www.periodicoshumanas.uff.br/index .php/ecos/article/view/1008

Lei $n^{\circ} 10.216$, de 6 de abril de 2001. Dispõe sobre a proteção e os direitos das pessoas portadoras de transtornos mentais e redireciona o modelo assistencial em saúde mental. Recuperado de http://www.planalto.gov.br/ccivil_03/leis/le is 2001/110216.htm

Lemos, A., Neto, A. V., Barbosa, D. F., Pereira, J. B., Ferreira, M. H., \& Valerio, R. (2007). Reflexões sobre a importância da psicologia na organização. Maringá Management: Revista de Ciências Empresariais, 4(1), 43-50.

Lénine, V. I. (1993). As Três Fontes e as Três partes Constituticas do Marxismo. (Edições Avante!, Trad.). Recuperado de https://www.marxists.org/portugues/lenin/1 913/03/tresfont.htm

Lima, M. (2005). Atuação psicológica coletiva: uma trajetória profissional em unidade básica. Psicologia em Estudo, 10(3), 431-440. doi: 10.1590/S141373722005000300011

Marochi, M. L. G. (2002). Considerações sobre modelos de produção e a psicologia do trabalho. Rev. FAE, 5(1), 15-28.

Recuperado de https://revistafae.fae.edu/revistafae/article/v iew/450

Marx, K. (1993). Manuscritos EconômicoFilosóficos (70a. ed.). Lisboa. (Originalmente publicado em 1844).

Marx, K. (1998). Teses sobre Feuerbach. In K. Marx, A Ideologia Alemã (L. C. de Castro e Costa, Trad., 2a. ed.). São Paulo, SP: Martins Fontes. (Originalmente publicado em 1845).

Marx, K. (2008). Contribuição à Crítica da Economia Política (F. Fernandes, Trad., 2a. ed.). São Paulo, SP: Expressão Popular. (Originalmente publicado em 1859).

Marx, K. (2013). O capital: crítica da economia política: Livro I: o processo de 
produção do capital (R. Enderle, Trad.). São Paulo, SP: Boitempo. (Originalmente publicado em 1867).

Musto, M. Prefácio. In I. F. Oliveira, I. L. Paiva, A. L. F. Costa, K. Amorim, F. Coelho-Lima (Orgs.), Marx hoje: pesquisa e transformação social (pp. 15-24). São Paulo, SP: Outras Expressões, 2016.

Pereira, A. S. (2009). Práxis da Psicologia Organizacional: atuação do Psicólogo organizacional na cidade de Teresina - PI. In Anais do XV Encontro Nacional da Associação Brasileira de Psicologia Social. Maceió: Faculdade Integrada Tiradentes.

Petit, F., \& Dubois, M. (1998). Introdução à Psicologia das organizações. Portugal, Lisboa: Instituto Piaget.

Portaria no 336, de 19 de fevereiro de 2002.

Estabelece as diferentes modalidades de Centro de Atenção Psicossocial - CAPS. Recuperado de http://bvsms.saude.gov.br/bvs/saudelegis/g m/2002/prt0336_19_02_2002.html

Robbins, S. P., Judge, T., \& Sobral, F. (2010). Comportamento organizacional: teoria e prática no contexto brasileiro (14a. ed.). São Paulo, SP: Pearson.

Schein, E. H. (1969). A Psicologia nas Organizações (M. G. S. BENTO, Trad.). Portugal, Lisboa: Clássica Editora.

Spector, P. E. (2012). Psicologia nas Organizações. (C. Yamagami, Trad.) (4a. ed.). São Paulo: Saraiva.

Tractenberg, L. (1999) A complexidade nas organizações: futuros desafios para o psicólogo frente à reestruturação competitiva. Revista Psicologia, Ciência e Profissão, 19(1)14-29. doi: 10.1590/S1414$\underline{98931999000100003}$

Veronese, M. V. (2003). Na direção de uma psicologia social crítica do trabalho. Rio Grande do Sul: PUCRS.

Womack, J., Jones, D. T., \& Roos, D. (1992) A máquina que mudou o mundo. (4a.ed.) São Paulo: Campus.

Zanelli, J. C., Borges-Andrade, J. E., \& Bastos, A. V. B. (2004). Psicologia, organizações e trabalho no Brasil (2a. ed.) Porto Alegre: Artmed.

\section{Dados sobre os autores:}

- Maísa Martins Lopes Araújo Brito: Graduanda em Psicologia pela Faculdade Católica Dom Orione. Coordenadora do núcleo da Associação Brasileira de Psicologia Social de Araguaína, Integrante da Comissão Especial Psicologia e Povos do Cerrado do Conselho Regional de Psicologia 23.

- Samuel de Menezes Pereira: Graduando em Psicologia pela Faculdade Católica Dom Orione. Interesse nos temas: Análise do Comportamento, Políticas Públicas e Psicologia Educacional.

- Gilson Gomes Coelho: Possui graduação em Psicologia pela Universidade Federal de Mato Grosso do Sul, Campus de Corumbá (2009), mestrado em Psicologia pela Universidade Estadual de Maringá (2015). Doutorando em Psicologia (Psicologia e Sociedade) pela Universidade Estadual Paulista "Júlio de Mesquita Filho", campus de Assis. Atualmente é Professor da Faculdade Católica Dom Orione.

\footnotetext{
Declaração de Direito Autoral

A submissão de originais para este periódico implica na transferência, pelos autores, dos direitos de publicação impressa e digital. Os direitos autorais para os artigos publicados são do autor, com direitos do periódico sobre a primeira publicação. Os autores somente poderão utilizar os mesmos resultados em outras publicações indicando claramente este periódico como o meio da publicação original. Em virtude de sermos um periódico de acesso aberto, permite-se o uso gratuito dos artigos em aplicações educacionais e científicas desde que citada a fonte conforme a licença CC-BY da Creative Commons.
} 